\title{
Cloning and characterization of endo- $\beta-1,4$-glucanase genes in the common wheat line three pistils
}

\author{
Zaijun Yang, Zhengsong Peng, Shuhong Wei and Yan Yu \\ Key Laboratory of Southwest China Wildlife Resources Conservation, China West Normal University, \\ Nanchong City, Sichuan, People's Republic of China.
}

\begin{abstract}
In this work, we report the cloning and characterization of endo- $\beta$-1,4-glucanase (EGase) genes (TaEG) in the common wheat line three pistils. Three TaEG homoeologous genes (TaEG-4A, TaEG-4B and TaEG-4D) were isolated and found to be located on chromosomes 4AL, 4BS and 4DS, respectively. The three genes showed high conservation of their coding nucleotide sequences and 3 untranslated region. The putative TaEG protein had a molecular mass of $69 \mathrm{kDa}$, a theoretical pl of 9.39 and a transmembrane domain of 74-96 amino acids in the N-terminus that anchored the protein to the membrane. The genome sequences of TaEG-4A, TaEG-4B and TaEG-4D contained six exons and five introns. All of the introns, except for intron IV, varied in length and sequence composition. Phylogenetic analysis revealed that TaEG was most closely related to rice (Oryza sativa) OsGLU1. The TaEG transcript levels increased significantly during the subsidiary pistil primordium differentiation phase (spike size $\sim 7-10 \mathrm{~mm}$ ) in Chuanmai 28 TP (CM28TP). These data provide a basis for future research into the function of TaEG and offer insights into the molecular mechanism of the three pistils mutation in wheat.
\end{abstract}

Keywords: cloning, endo- $\beta$-1,4-glucanase, three pistils line, wheat.

Received: April 26, 2013, Accepted: June 3, 2013.

\section{Introduction}

Endo- $\beta$-1,4-glucanases (EGases) are enzymes that hydrolyze polysaccharides containing a $1,4-\beta$-glucan backbone and are produced by prokaryotes and eukaryotes (Henrissat et al., 1989; Beguin, 1990; Watanabe et al., 1998; Byrne et al., 1999; Rosso et al., 1999). These enzymes have also been classified as cellulases because of their central role in cellulose degradation and their potential to modify cellulose-containing materials (Bisaria and Mishra, 1989; Beguin, 1990; Beguin and Aubert, 1994). Sequence analysis has shown that all cloned plant EGases can be classified into two subfamilies (Nicol et al., 1998). One of these subfamilies consists of soluble secreted EGases such as avocado Cel1, pepper CX1 and tomato Cel2 that are expressed specifically during fruit ripening (Christoffersen et al., 1984; Lashbrook et al., 1994; Ferrarese et al., 1995), while others such as bean BAC1, soybean SAC1 and elder JET1, are associated with abscission (Tucker et al., 1988; Kemmerer and Tucker, 1994; Taylor et al., 1994). The other subfamily consists of membrane-anchored proteins located in the plasma membrane that also contribute to nor-

Send correspondence to Zaijun Yang. Key Laboratory of Southwest China Wildlife Resources Conservation, China West Normal University, Nanchong City, 637009, Sichuan, People's Republic of China. E-mail: zaijunyang@cwnu.edu.cn. mal cellulose formation (Brummell et al., 1997a; Nicol et al., 1998; Del Campillo, 1999; Molhoj et al., 2001). This subfamily includes the Arabidopsis KOR gene and the $O$. sativa OsGLU1 gene that are involved in cell elongation (Nicol et al., 1998; Lane et al., 2001; Zhou et al., 2006).

The common wheat (Triticum aestivum L.) line three pistils (TP), which was selected by Peng (2003) from the "trigrain" wheat cultivar, is a valuable mutant for improving wheat yield. Since the TP mutation has normal spike morphology but produces three pistils per floret it has potential for increased grain number per spike. In a previous study, a sequence from an expressed sequence tag (EST) was initially identified in a TP mutation in wheat using an annealing control primer system (ACP) (Yang et al., 2011). Blast searches of this sequence against the GenBank database revealed that it was homologous to the EGase gene. To our knowledge, the role of EGase genes in wheat development has not yet been reported.

As part of an investigation into the function of the wheat EGase gene (TaEG) in pistil development in this work we have cloned, characterized and phylogenetically analyzed the TaEG gene in the common wheat line three pistil. We also examined the expression patterns of this gene in different developmental stages of young spikes. 


\section{Materials and Methods}

\section{Plant material}

Chuanmai 28 TP (CM28TP), a near-isogenic line of the common wheat line Chuanmai 28 carrying the Pis1 gene derived from the TP mutant (Yang et al., 2012), and the recurrent parent $T$. aestivum cv. Chuanmai 28 (CM28) were used in this study. The near-isogenic line and the recurrent parent were cultivated in the field at the China West Normal University in Nanchong, China. Young spikes at the reproductive stage were collected and examined with an Olympus SZX9 stereomicroscope to accurately determine their developmental stage. Subsidiary pistil spikes in the primordial stage of differentiation (spike size $\sim 7-10 \mathrm{~mm}$ ) were used as a source of RNA and DNA for cloning the cDNA and sequencing the TaEG gene. Spikes of CM28TP and CM28 at various developmental stages (spikes 2-5, 5-7, 7-10, 10-13, 13-15, 15-17 and 17-20 $\mathrm{mm}$ in length) were selected for real-time PCR. In addition, the nullisomic-tetrasomic (NT) lines and ditelosomic (Dt) lines Dt1AL, Dt1AS, Dt2AS, Dt3AL, Dt3AS, Dt4AL, N4AT4B, Dt5AL, N5AT5B, Dt6AL, Dt6AS, Dt7AL, Dt7AS, Dt1BL, Dt1BS, Dt2BL, N2BT2A, Dt3BL, Dt3BS, Dt4BL, Dt4BS, Dt5BL, N5BT5D, Dt6BS, N6BT6D, Dt7BL, Dt7BS, Dt1DL, Dt1DS, Dt2DL, Dt2DS, Dt3DL, Dt3DS, Dt4DL, Dt4DS, Dt5DL, N5DT5A, Dt6DL, Dt6DS, Dt7DL and Dt7DS derived from CS (Sears, 1954; Endo and Gill, 1996) were used for the chromosomal mapping of TaEG.

\section{DNA and RNA isolation}

Genomic DNA was isolated from young spikes of CM28TP and CM28 and fresh leaves of the NT and Dt lines, as described by Porebski et al. (1997). The DNA was dissolved in Tris-EDTA (TE) buffer and stored at $-20{ }^{\circ} \mathrm{C}$. Total RNA was isolated from young spikes as described by Manickavelu et al. (2007). The RNA was dissolved in RNase-free double distilled water $\left(\mathrm{ddH}_{2} \mathrm{O}\right)$ and stored at $-70{ }^{\circ} \mathrm{C}$. The quality of the DNA and RNA was confirmed by agarose gel electrophoresis and the nucleic acid concentrations were determined spectrophotometrically based on the 260/280 $\mathrm{nm}$ absorbance ratio.

\section{Cloning and chromosomal mapping of TaEG}

A TaEG EST (DETP-3) was initially identified in the three pistils mutation of wheat by using an annealing con- trol primer system (ACP) (Yang et al., 2011). Blast search analysis indicated that a full length cDNA (GenBank ID: AK373303) in barley shared perfect identity with the TaEG EST. The PCR primer pair TaEG-1 was designed with Primer Premier 5.0 based on the cDNA of AK373303 (Table 1). The cDNA and genomic DNA sequences were amplified using the same primers (TaEG-1). PCR amplification was done in a thermocycler (My-Cycle, Bio-Rad, San Diego, CA, USA) in a volume of $50 \mu \mathrm{L}$ containing $100 \mathrm{ng}$ of genomic DNA or reverse transcriptase reaction product (see below for details), $100 \mu \mathrm{M}$ of each dNTP, $1.5 \mathrm{mM}$ $\mathrm{Mg}^{2+}, 1 \mathrm{U}$ of Taq DNA polymerase, $0.4 \mu \mathrm{M}$ of each primer and 1 PCR buffer. The PCR cycling conditions included pre-denaturation at $94{ }^{\circ} \mathrm{C}$ for 5 min followed by 35 cycles of $94{ }^{\circ} \mathrm{C}$ for $30 \mathrm{~s}, 60^{\circ} \mathrm{C}$ for $30 \mathrm{~s}$ and $72{ }^{\circ} \mathrm{C}$ for $4 \mathrm{~min}$, and a final extension at $72{ }^{\circ} \mathrm{C}$ for $10 \mathrm{~min}$. The amplified products were visualized by gel electrophoresis in 1\% agarose gels and then documented with a Gel Doc 2000TM system (Bio-Rad). The target DNA bands were recovered and purified from the gels using Qiaquick Gel extraction kits (QIAGEN, Shanghai, China). The purified PCR products were cloned in the pMD-19T vector according to the manufacturer's instructions (Takata, Dalian, China). Transformants were plated on LB agar containing ampicillin. Clones with inserts were identified using blue/white colony selection. Positive clones were then screened and sequenced by Taihe Biotechnology Co. Ltd. (Beijing, China).

The chromosomal location of TaEG was mapped using the genomic DNA of 36 Dt lines and 5 NT lines (see above). The authenticity of the Dt lines and NT lines was confirmed with SSR markers before use. The gene-specific primers for TaEG-IN3 (Table 1) were designed based on intron which shows clear sequence variations among chromosomes A, B and D (Figure 1).

\section{Molecular characterization of TaEG}

The sequence data were analyzed with GenScan software. The open reading frame (ORF) of the cDNA sequence was searched using ORF finder software. A computation tool from the Swiss-Prot/TrEMBL entries was used to calculate the isoelectric point (pI) and molecular mass (Mr) of TaEG. The deduced TaEG sequence was investigated for the presence of signal peptide cleavage sites and transmembrane helices using software available through

Table 1 - Primers used in this study.

\begin{tabular}{llll}
\hline PCR target & Primer & Forward & Reverse \\
\hline Genomic and cDNA sequences & TaEG-1 & CCCTTCCGTTCCCATTCCAAGC & ACATGGCATGGTGATGATACT \\
Chromosomal location & TaEG-IN3 & GGATAATAAGCTCCCTGGTG & TACAATCGTAAGTGCCCTGT \\
Real-time PCR & TaEG-2 & GCGGGCAACGCTGGTCTA & GGGAACATTGGCGGCACA \\
Internal control & Ubiquitin & AAGGCGAAGATCCAGGACAAG & TGGATGTTGTAGTCCGCCAAG \\
& Actin & ACGCTTCCTCATGCTATCCTTC & ATGTCTCTGACAATTTCCCGCT \\
\hline
\end{tabular}




\begin{tabular}{|c|c|c|}
\hline $\mathrm{TaEG}-4 \mathrm{~A}$ & GTGTTCAGCTGGGATAATAAGCTCCCTGGTGCACAGGT. AATGTATTAGCGTATCTTGGTTTCTTTTAAT & 1769 \\
\hline $\mathrm{TaEG}-4 \mathrm{~B}$ & GTGTTCAGCTGGGATAATAAGCTCCCTGGTGCACAGGTAAATATATTTGTGTAACTTGGTTTCGTTTAAT & 1770 \\
\hline$E G-4 D$ & GTGTTCAGCTGGGATAATAAGCTCCCTGGTGCACAGGT. AATGTATTAGCGTATCTTGGTTTCGTTTAAT & 1782 \\
\hline$-4 A$ & TCTCAAGACATTCCCCATGCTGACCCATTGGCATTTTAGTTTGCATGATACTCCCTTCCTAAACTAATAT & 83 \\
\hline$-4 B$ & TCTTGAGACATTCCCCATGCTGACCCATTGGCATTTTAGTTTGCATGATACTTGTCAAGTAC. & 1832 \\
\hline$-4 D$ & TCGCAAGACATTCCCCATGCTGACCCATTGGCATTTTAGTTTGCATGATACTCCCTCCGTAAACTAATAT & 1852 \\
\hline$-4 A$ & AGAAGTGTTTGGATTACTACTTTAGTGATCTAAACGCTCTTATATTAGTTTATAGAGgGAATAC. & \\
\hline$-4 B$ & ТСССТСССТСССА & \\
\hline$-4 D$ & AAGAGTGTATAGATCACTAAAGTAGTGATCTAAACGCTCTTATATTAGTTTACAGAGTCCCTCCGTCCCA & \\
\hline$-4 \mathrm{~A}$ & TAATGTAAGATG. TTTTTGACACTTCTCCCTCCGTTCCGAATTACTTGTCGCAGGTATGGATGTATCTAT & 9 \\
\hline$-4 B$ & TTTTGACACCACACGAGAGTCAA. & 88 \\
\hline$-4 D$ & TAATGTAAGATG. TT. & 6 \\
\hline$-4 A$ & ATGTATTTTAGTTCTAGATACATCCATTTCTGCGACGAGTAATTTGGAACGGAGGGAATACACTAGAGTC & 0 \\
\hline$-4 B$ & AAAAACCGTCTTACATTATGGGACCGGAGGGAGTAGATTCCATG & 19 \\
\hline$-4 D$ & . . . . TTTTGGCACTACACTAGAGTCAAAAGCCATCTTACATTATGGGACCGGAGGGAGTAGATTCCATG & \\
\hline$-4 A$ & AAAAACCGTCTGACCGTCAGGTTAGAGTACTATTGGGACCAAATTTCTTTATAATATCTCACCCAGTTTA & \\
\hline$-4 B$ & TCTAACACACTGACCGTCAGGTTATAGTACTATCGTGACCAAATTTCTTTATAATATGTCACCCAGTTTA & \\
\hline$-4 \mathrm{D}$ & TCTAACACACTGACCGTCAGGTTATAGTACTATTGGGACCAAATTTCTTTATAATATCTCACCCAGTTTA & \\
\hline$-4 A$ & CCTGCAGTACTAGTAAAGCGTGTGGTCAACTTGTCCTACCATGTGATAAGCATTAATGCTGACTAAGTAC & 2 \\
\hline$-4 B$ & CCTGCGGTACTAGTAAAGCGTGTAGCCAGCTTGTCCTACCATGTGATAAGCATTAATGCTGCCTAGGTAC & 20 \\
\hline-40 & CCTGCAGTACTAGTAAAGCGTGTAGTCAACTTGTCCTACCATGTGATAAGCATTAATGCTGCCTAAGTAC & 21 \\
\hline$-4 A$ & AGGGCACTTACGATTGTAGCACAAAAGGTTTCCTGCTTGGTGGATATACCAAGGATTCTGTTGAAACCAT & \\
\hline$-4 B$ & AGGGCACTTACGATTGTAGCACAAAAGGTTTCCTGCTTGGTGGATATACCTAGGATTCTGTTGAAACCAT & \\
\hline$-4 D$ & AGGGCACTTACGATTGTAGCACAAAAGGTTTCCTGCTTGGTGGATATACCAAGGATTCTGTTGAAACCAT & \\
\hline
\end{tabular}

Figure 1 - Alignment of the intron III sequences of TaEG-4A, TaEG-4B and TaEG-4D. The forward and reverse TaEG-IN3 primers used for chromosome location are boxed.

the SignalP 4.1 and SCOP servers. For homology analysis, the amino acid sequence of TaEG was compared with the sequences of other species using Blast 2.1.

Multiple sequence alignment and phylogenetic analysis

The deduced amino acid sequence of TaEG was aligned with the EGase genes reported for other species using the ClustalW program (Thompson et al., 1994). Neighbor-joining trees of the EGase genes were generated with MEGA software version 5.0 (Saitou and Nei, 1987; Tamura et al., 2007) with 1000 bootstrap replicates. Gaps were treated as missing values. The amino acid sequences of EGase genes from Arabidopsis thaliana (L.) Heynh (AtCel1: X98544, KOR: NP_199783), Oryza sativa L. (OsGLU1: EEE58992), Solanum lycopersicum L. (TomCel2: U13055, TomCel3: U78526, TomCel8:
AF098292), Piper nigrum L. (CcCel3: X97189), Nicotiana tabacum L. (NtCel2: AF362948, NtCel8: AF362949), Pyrus communis L. (PeEG2: BAC22691, Cel1: BAF42036), Mangifera indica L. (MiCel1: EF608067), Brassica napus L. (Cel16: CAB51903) and Gossypium barbadense L. (Cel: ADY68791) were obtained from NCBI.

Real-time PCR

Total RNA was isolated from spikes of the nearisogenic line CM28TP and its recurrent parent, CM28, at various developmental stages (2-5, 5-7, 7-10, 10-13, 13-15, 15-17 and 17-20 $\mathrm{mm}$ in length). The cDNA was synthesized using a PrimeScript Perfect real-time RT reagent kit (TaKaRa, Dalian, China). The primers for TaEG-2 (Table 1) were designed using Primer Express 2.0 software to amplify 101-bp fragments of the TaEG gene. Real-time as- 
says were done with SYBR green dye (TakaRa) using a Bio-Rad CFX96 real-time PCR platform. All of the samples were analyzed in triplicate and the fold change in RNA transcripts was calculated by the $2^{-\Delta \Delta C t}$ method (Livak and Schmittgen, 2001) with the wheat housekeeping genes ubiquitin (DQ086482) and actin (AB181911) as internal controls (Hama et al., 2004; Yamada et al., 2009).

\section{Results}

\section{Cloning and chromosomal location of genomic and cDNA sequences}

Cloning followed by PCR product analysis resulted in the identification and isolation of three genomic sequences (3625, 3510 and 3574 bp long) from CM28TP. Three bands (489, 435 and 374 bp) were amplified in CM28TP with gene-specific primers of TaEG-IN3. NT and Dt line analysis indicated that the TaEG-IN3 primer set amplified the expected three bands from all the NT and Dt lines, with the exception of DT4AL (lacked the 489-bp band), N4A-T4B (lacked the 489-bp band), Dt4BS (lacked the 374-bp band) and Dt4DS (lacked the 435 bp band) (Figure 2). Further analysis showed that the longest PCR product (3625 bp) was located on the long arm of chromosome $4 \mathrm{~A}$, the intermediate product ( $3574 \mathrm{bp}$ ) on the short arm of chromosome $4 \mathrm{D}$ and the shortest product ( $3510 \mathrm{bp}$ ) on the short arm of chromosome 4B. The three homologous genes were tentatively designated as TaEG-4A, TaEG-4D and TaEG-4B, respectively. The sequences were deposited in GenBank under accession numbers KC521526, KC521527 and KC521528.

The cDNA from young spikes of CM28TP amplified with the TaEG-1 primer pair yielded a fragment of $\sim 2.1 \mathrm{~kb}$. The PCR product was cloned into the PMD-19T vector and 15 clones were sequenced. Three distinct sequences of $2061 \mathrm{bp}, 2084 \mathrm{bp}$ and $2087 \mathrm{bp}$ were identified (accession numbers: AC521523, AC521524 and AC521525, respectively), indicating that the band of $\sim 2.1 \mathrm{~kb}$ included comigrating cDNA of different homologous genes. The three homologous genes shared $100 \%$ homology in their coding and 3' untranslated regions. The lengths of the 5' untranslated region were $103 \mathrm{bp}, 126 \mathrm{bp}$ and $129 \mathrm{bp}$ for TaEG-4A, TaEG-4B and TaEG-4D, respectively. The open reading frame (ORF) of TaEG was $1869 \mathrm{bp}$ and coded for a deduced protein of 622 amino acids. Primary structure analysis using Swiss-Prot/TrEMBL revealed that the molecular mass of the putative TaEG protein was $69 \mathrm{kDa}$ with a theoretical $\mathrm{pI}=9.39$. The putative $\mathrm{TaEG}$ protein lacked signal peptide cleavage sites but had a 74 96 amino acid transmembrane domain. BLAST searches showed that the TaEG belonged to glycosyl hydrolase family 9 (Henrissat et al., 1989). Sequence alignment suggested that $\mathrm{TaEG}$ had high homology with other plant EGase proteins, all of which contained four Cys residues and two putative glycosyl hydrolase active sites, namely, 'SY-VG-G-YPVHHR' and 'F-DVR-N-NYTE-TLAGAN' (Figure 3).

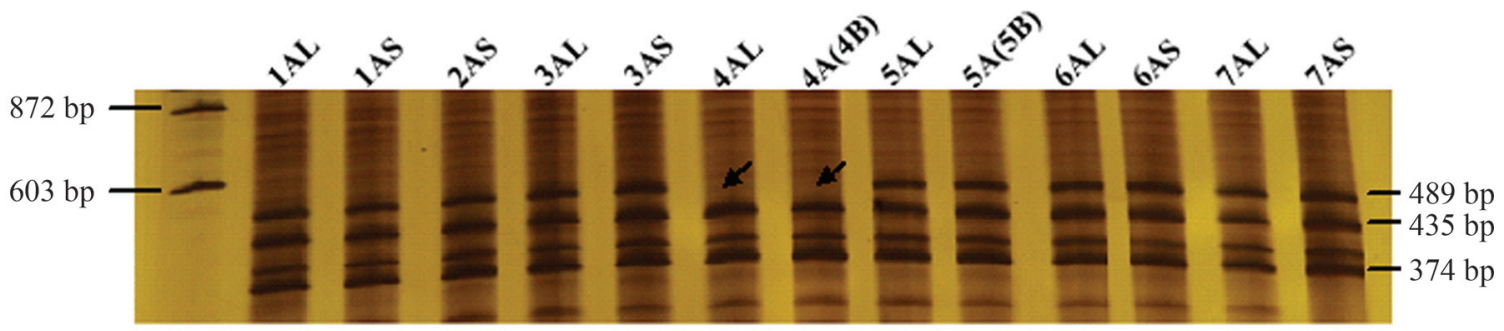

b
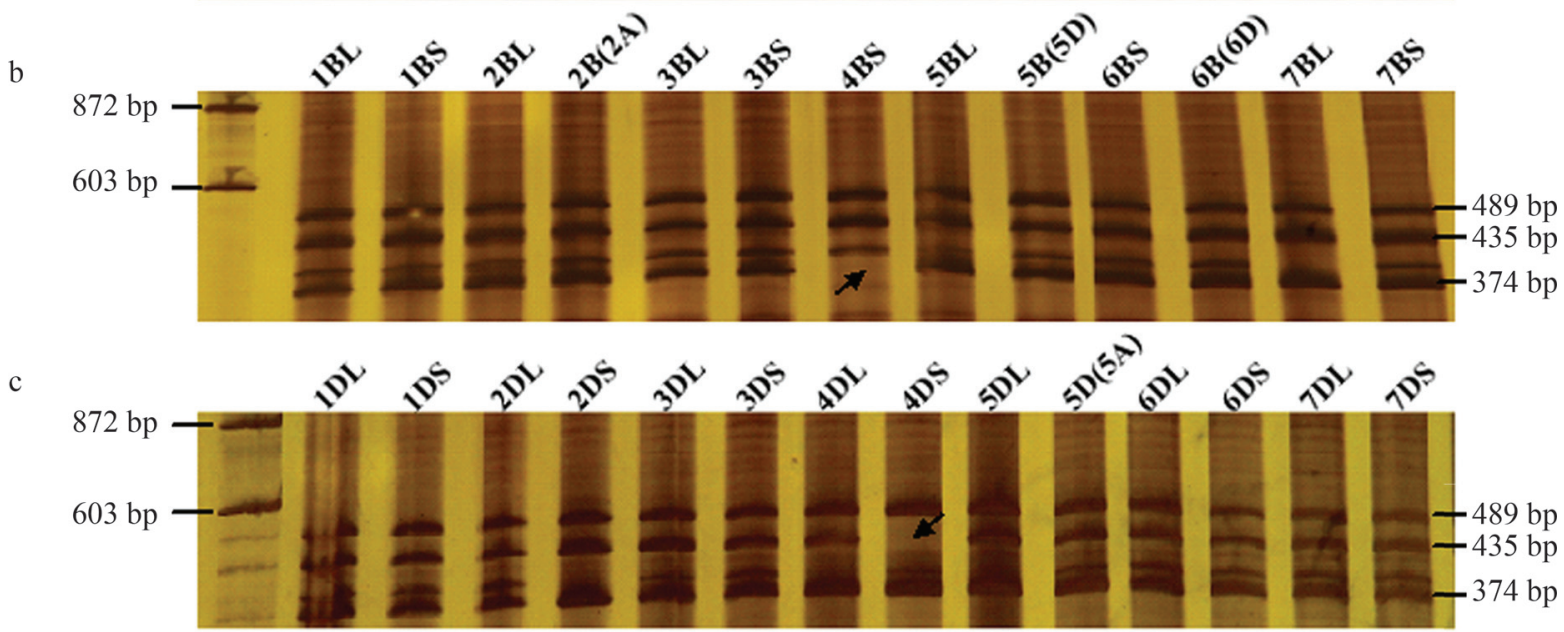

Figure 2 - Chromosome mapping of the TaEG gene. DNA size markers are shown on the left of the gel. (A) TaEG-4A located on the long arm of chromosome 4A. (B) TaEG-4B located on the short arm of chromosome 4B. (C) TaEG-4D located on the short arm of chromosome 4D. Missing fragments are indicated by arrows. 
CEL1 MSMYGRDPWGGPLE INTTDSATDDDRSRNLQDLDRAALSSRPLDETQQSWLLGPSG. EQ. KKKKYVDLGCI IVSRKIFVWTVGTLLVSAFLAGF I

CEL16 .. MYGRDPWGGPLEIHATDSATDDDRSRNLNDIDRAAL. SRPLDETQQSWLLGPTE. OK. KKKYVDLGCI IVSRKIFVWTVGT IVAA. ALLAGF I

CEL .. MYGRDPWGGPLEINATDSATDDDRSRNLQDLDRAAL. SRPLDETQQSWLLGPGE. QK. KKKKYVDLGCI IVSRKIFVWTVGTLLVSALLAGLI

OSGLU1 MSMYGRDPWGGPLEICH. DSATDDDRSRNL. DLDRGAL. SRTLDETQQSWLLAGPGDQGRKKKKYVDLGGLVVSRKLFVVTVGVLLAAAVFAGLV

KOR _. MYGRDPWGGPLEINTADSATDDDRSRNLNDLDRAAL. SRPLDETQQSWLLGPTE. QK. KKKYVDLGCI IVSRKIFVWTVGTLVAA. ALLAGF I

TOMCEL3 .. MYGRDPWGGPLEIHTADSATDDDRSRNLQDFDRAAM. SRSLDETQQSWLLGPTE. Q. . KKKKYVDLGCI IVSRKIFKWTVGC I I AAALLAGF I

TAEG

MSMYGRDPWGGPLE ICH. DSATDDDRSRNL. DLDRAAL. SRTLDETQQSWLLAGPGDQGRKKKRYVDLGCLLVSRKLFLWTLGLLLAAAALAGIA

CEL1 TL IVKTVPRHRHSRPPPDNYTLALRKSLMFFNAQRSGKLPKHNNVSWRGNSCLRDGN. DPSTTFKDLAGGFYDAGDA IKFNFPASFAMTMLSWGV

CEL16 TL I VKTVPRHHRKTPPPDNYT I ALHKALKFFNAQKSGKLPRHNNVSWRGNSGLQDGKGDSGSFYKDLVGGYYDAGDA I KFNFPMAYAMTMLSWSV

CEL TLIVKTVPRHHHRHSPPDNYTLALHKALMFFNAQRSGKLPKHNNVSWRGNSGLQDGKSDPSVLMKDLVGGYYDAGDAIKFNFPASFSMTMLSWSV

0SGLU1 AGI AKA I PRHHRPPPPPDDFTVALRKALMFFNAQKSGKLPKNNNVHWRGNSCMKDGLSDPAVGRS. LVGGYYDAGDAVKFNFPAAFSMTLLSWSV

KOR TLIVKTVPRHHPKTPPPDNYT I ALHKALKFFNAQKSGKLPKHNNVSWRGNSGLQDGKGETGSFYKDLVGGYYDAGDA IKFNFPMAYAMTMLSWSV

TOMCEL3 TM IVKLVPRHKHHNPPPDNYTLALRKALMFFNAQKSGKLPKHNNVSWRGNSCLQDGKSDDSTMFKNLVGGYYDAGDA IKFNFPQSFALTMLSWSV

TAEG AGIAKAVPRHQAPPAPLDQFTLALRKALMFFNAQKSGKLPKHNNVPWRGDSCLKDGRSDQTSRRD. LSGGYYDGGSAVKFNFASAFSMTLLSWSV

CEL1 IEYSAKYEAAGELSHVKEI IKWGSDYFLKTFNHSADS I DRLVAQVGVGSTAGGSTTPNDHYCWMRPEDIDYQRPVSQCHS. "SंDLAAEMAAALAA

CEL16

CEL IEYSAKYEAAGELVHVKEL I KWGTDYFLKTFNSTADS I DDLVSOVGSGNTDDGSTDPNDHYCWMRPEDMDYKRPVTTCNG C'SDLAAEMAAALAS IEYSAKYEAAGELNHVKE I I KWGTDYLLKTFNNTADT I DR I AAQVG I GDTSGGSSAPNDHYCWMRPEDIDYPRPVYECHS. 'ं: ': SDLAAEMAAALA

OSGLU1

KOR

TOMCEL3

TAEG IEYSAKYEAVGELGHIRDT I KWGADYFLKTFNSTADT I DRVVMQVGSGATSPGSTQPNDHYGWMRPEDIDYPRPVVECHA IEYSAKYEAAGELTHVKEL I KWGTDYFLKTFNSTADS I DDLVSOVGSGNTDDGNTDPNDHYGWMRPEDMDYKRPVTTCNGG'SDLAAEMAAALAS

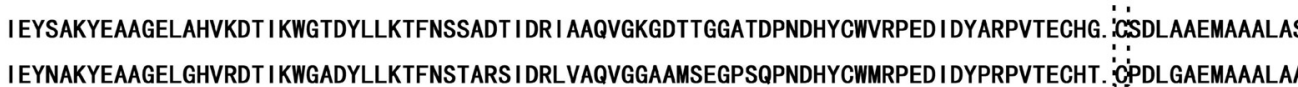

CEL1 SS IVFKDNKAYSQKLVHGAKTLFRFSREQ . RGRYSAGGSTDAATFYNSTSYWDEF I WGGAWMYYATGNSSYLQLATTPGLAKHAGAFWGGPDYG

CEL16 AS IVFKDNREYSKKLVHGAKTVYQFGRTR. . RGRYSAGTA. ESAKFYNSSMYWDEF I WGGAWLYYATGNVTYLDL I TKPTMAKHAGAFWGGPYYG

93 89 90 92 89 89 92 187 184 185 186 184 184 186 281 279 279 280 279

KOR

TOMCEL3 AS IVFKDNKEYSKKLVHGAKVVYQFGRTR. . RGRYSAGTA. ESSKFYNSSMYWDEF I WGGAWMYYATGNVTYLNL I TQPTMAKHAGAFWGGPYYG

CEL1 AS I VFRDNRAYSHKLLHGATTVWDFARKGGSROTYSVPRS. DAAKFYNSTAYWDEY I WGGSWMYLATGNSSYLQFATDTKLAKNAHIYSRPPNYG VLSWDNKLAGAQVLLSRLRLFLSPGYPYEE ILRTFHNQTSI I ṀSYYYPVFTTFNRTKGGL I QLNHGRPQPLQYVVNAAFLATLYSEYLDAADTPG VFSWDNKLAGAQLLLSRLRLFLSPGYPYEE IVRTFHNQTS I VMICSYLPYFNKFNRTRGGL I ELNHGDPQPLQYAANAAFLATLYSDYLDAADTPG VLSWDNKLAGAQVLLSRLRLFLSPGYPYEE ILSTFHNQTS I STSFLPVFTSFNTKGGL I QLNHGRPQPLQYVVNAAFLAALYSDYLDAADTPG :

CEL

OSGLU1

KOR VFSWDNKLTGAQVLLSRLRLFLSPGYPYEE ILRTFHNQTSI I I I MCSYLP IFKSFNRTKGGL I QLNHGRPQPLQYVVNAAFLASLYGDYLEAADTP VFSWDNKLAGAQLLLSRLRLFLSPGYPYEE ILRTFHNQTS I VMSY SYP I FNFNRTNGGL I ELNHGAPQPLQYSVNAAFLATLYSDYLDAADTPG VLSWDNKLTGAQVLLSRMRLFLSPGYPYEE ILRTFHNQTS I IMC'SYLP IFTSFNRTKGGL I QLNHGRPQPLQYVVNAAFLATLFSDYLAAADTPG

TOMCEL3

TAEG VFSWDNKLPGAQVLLSRLRLFLSPGYPYEEMLRTYHNQTS I ICSYLPNFRSFNRTKGGL I QLNHGQPQPLQYVVNAAFPASLFSDYLEAADTPG

CEL1

CEL16

CEL

OSGLU1

KOR TOMCEL3

TAEG WYGG̈GPNFYSTDVLREFAKTQI DYILGKNPRKMSYVVGFGNHYPKHVHHRGAS IPKN. KIKYSंÇKGGWKWRDTPKANPNT IDGAMVAGPDKHDGFR WYCGGNFYSTNVLREFARTQI DYILGKNPRKMSYLVGFGTKYPKHVHHRGAS I PKN. KVKYNCKGGWKWRDSKKPNPNT IEGAMVAGPDKRDGF

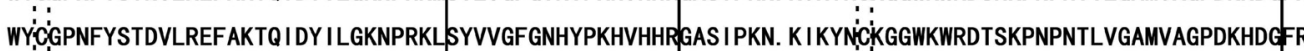
WY':GPHFYP I ETLRNFARTQIEY ILGKNPLKMSYVVGYGNRYPKRVHHRIGAS IPKN. GVHYG'CKGGWKWRETKKPNPN I IVGAMVAGPDRHDGFK

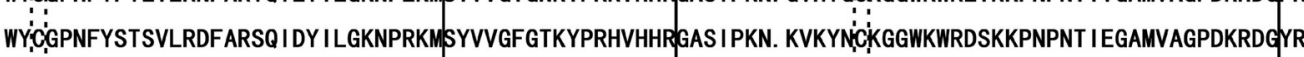
WY'GCPNFYSTDVLRKFAETQI DY ILGKNPRKMSYVVGFGNHYPKHVHHRIGAS I PKN. KVKYNCKGGWKYRDSSKANPNT IVGAMVAGPDKHDGFR 469 466 466 467 466 464 469

CEL1

CEL16

CEL

OSGLU1

KOR

TOMCEL3

TAEG
621

Figure 3 - Alignment of the deduced amino acid sequence of TaEG with other plant EGase sequences. Four Cys residues and two putative glycosyl hydrolase active sites are indicated by the dotted line and solid line frames, respectively. 


\section{Structure of the TaEG genomic sequences}

The TaEG-4A, TaEG-4B and TaEG-4D genomic sequences were $3625 \mathrm{bp}, 3510 \mathrm{bp}$ and $3574 \mathrm{bp}$ long, respectively; their alignment and comparison with the corresponding cDNA sequences revealed the complex structure of the three homologous genes that consisted of six exons and five introns (Figure 4). The five introns fulfilled the GT-AG relue but varied markedly in length and sequence composition. The length of intron III was $905 \mathrm{bp}, 792 \mathrm{bp}$ and $850 \mathrm{bp}$ in TaEG-4A, TaEG-4B and TaEG-4D, respectively, which was longer than the other four introns. Intron IV was $85 \mathrm{bp}$ long in the three genes and was the shortest of the five introns. Intron I was $395 \mathrm{bp}, 369 \mathrm{bp}$ and $376 \mathrm{bp}$ long in TaEG-4A, TaEG-4B and TaEG-4D, respectively. Intron II showed two lengths ( $88 \mathrm{bp}$ and $86 \mathrm{bp}$ ) in TaEG-4A, TaEG-4B and TaEG-4D whereas intron $\mathrm{V}$ had three lengths, i.e., $91 \mathrm{bp}, 92 \mathrm{bp}$ and $90 \mathrm{bp}$.

\section{Phylogenetic analysis of TaEG and plant EGases}

To construct the phylogenetic tree, EGases from $A$. thaliana (AtCel1 and KOR), O. sativa (OsGLU1), $S$. lycopersicum (TomCel2, TomCel3 and TomCel8), $P$. nigrum (CcCel3), N. tabacum ( $\mathrm{NtCel} 2$ and $\mathrm{NtCel} 8), P$. communis (PcEG2 and Cel1), M. indica (MiCel1), B. napus (Cel16) and G. barbadense (Cel) were analyzed. Figure 5 shows the tree obtained with the neighbor joining program using MEGA software and 1000 bootstrap replicates. Previous analysis identified two types of EGase in plants, namely, secretory EGase and transmembrane EGase, with the major difference between them being the presence of a signal peptide in the former and a transmembrane domain in the latter (Brummell et al., 1997a). In the present study, these EGases formed into two well-resolved clades (clades 1 and 2). Clade 1 contained eight members and the deduced proteins possessed a signal peptide, e.g., Tom Cel2, $\mathrm{NtCel} 2$ and PcEG2. Further inspection of clade 1 revealed the presence of two subclades (subclades 1 and 2), with the major difference between them being the presence (subclade 1) or absence (subclade 2) of a cellulose binding domain (CBD) (Zhou et al., 2004). Clade 2 contained seven members and the deduced proteins had a transmembrane domain, e.g., Tom OsGLU1, Cel16 and KOR. TaEG was located in clade 2 and showed a much greater similarity $(83 \%)$ to $O$. sativa

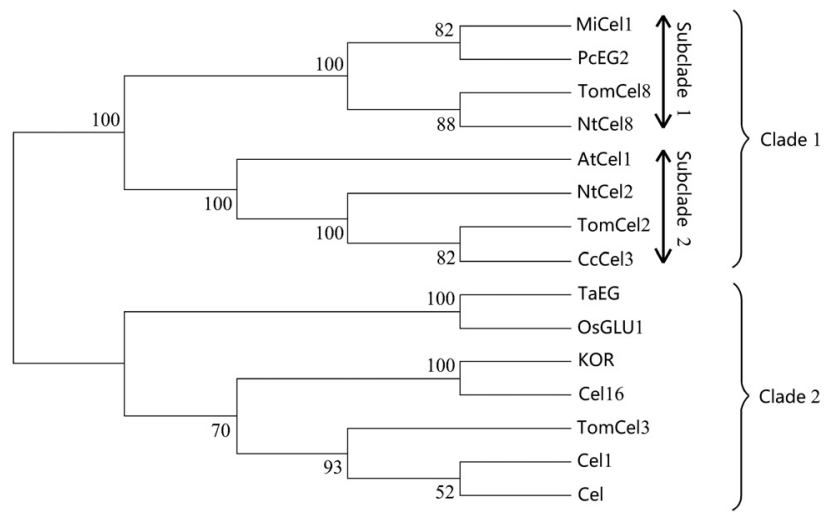

Figure 5 - Phylogenetic tree of TaEG and other homologous sequences. The numbers at the nodes indicate bootstrap values.

OsGLU1. Phylogenetic analysis also indicated that TaEG was a membrane-anchored protein.

\section{TaEG gene expression in developing spikes}

Real-time PCR was used to study the pattern of TaEG expression in different tissues during the developmental stages of young spikes. As shown in Figure 6, in young spikes of CM28TP at stages 2-5, 5-7, 10-13, 13-15, 15-17 and $17-20 \mathrm{~mm}$ the transcript levels were similar to those observed in CM28. However, the transcript levels in young spikes of CM28TP at stages 7-10 mm were 5.6-fold higher than in CM28 spikes at the same stage.

\section{Discussion}

An EST sequence (DETP-3) previously identified in the three pistil mutation of wheat using an annealing control primer system (ACP) was shown to have functions similar to those of the EGase gene (Yang et al., 2011). The EST was therefore tentatively designated as an $T$. aestivum endoglucanase gene (TaEG). In the present study, cDNA cloning and genome sequencing of TaEG from wheat showed that there are three homoeologous TaEG genes in wheat, namely, TaEG-4A, TaEG-4B and TaEG-4D located on chromosomes 4AL, 4BS and 4DS, respectively. The three homoeologous genes showed high conservation of the nucleotide coding sequences and 3 untranslated regions, with homologies up to $100 \%$. The putative TaEG

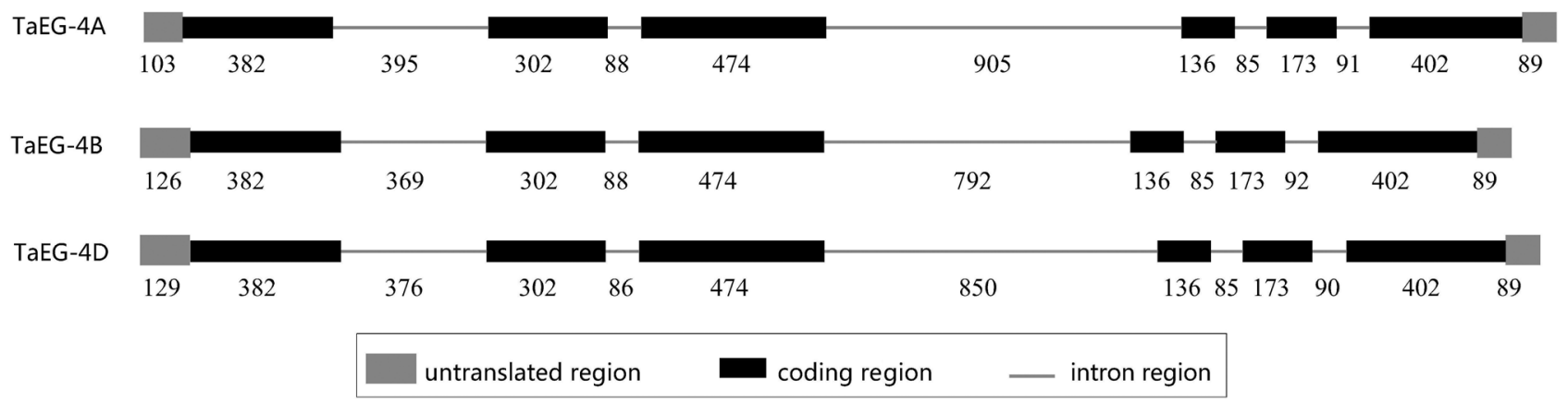

Figure 4 - Schematic representation of the TaEG gene. 


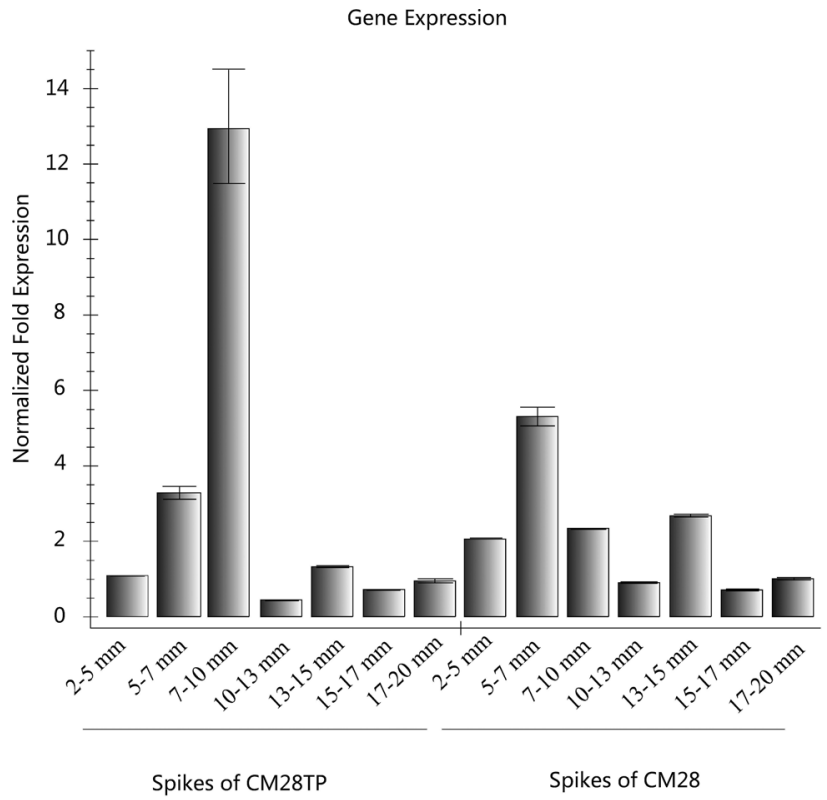

Figure 6 - TaEG expression assessed by real-time PCR. Total RNA was isolated from spikes of the near-isogenic line CM28TP and its recurrent parent CM28 at various developmental stages. Ubiquitin and actin were used as internal controls. The transcript levels are shown as relative values and the columns represent the mean \pm SEM of three replicates.

protein had a $\mathrm{Mr}$ of $69 \mathrm{kDa}$, a theoretical $\mathrm{pI}$ of 9.39 and a 74-96 amino acid transmembrane domain in the N-terminus. Despite variation in the nucleotide and amino acid sequences of TaEG from different plants, all of these proteins contained four Cys residues and two putative glycosyl hydrolase active sites (SY-VG-G-YP-VHHR and F-DVRN-NYTE-TLAGAN) (Figure 3). The genome sequences of TaEG-4A, TaEG-4B and TaEG-4D contained six exons and five introns, all of which (except for intron IV) varied in length and sequence composition.

Endo- $\beta$-1,4-glucanases have been classified into two subfamilies (Nicol et al., 1998). One subfamily consists of soluble secreted enzymes that contain an N-terminal signal peptide and EGase domain; these enzymes are located in the periplasm where they function as cell wall-softening enzymes that modify the cell wall. The other EGase subfamily consists of membrane-anchored proteins that have a predicted N-terminal transmembrane anchor motif (Brummell et al., 1997a). TaEG, like KOR and TomCel3, belongs to the latter subfamily and contains a transmembrane domain located between amino acids 74 to 96 . The precise function of membrane-anchored EGases is currently unclear, but these enzymes are located in the plasma membrane and participate in cellulose metabolism in the inner layers of the cell wall (Brummell et al., 1997a; Nicol et al., 1998; Del Campillo, 1999; Molhoj et al., 2001). Some membrane-anchored EGases are involved in cell elongation. In tomato vegetative tissues the highest levels of TomCel3 mRNA were found in the most actively growing cells, in the expanding zones of young hypocotyls and in young expanding leaves (Brummell et al., 1997b). The Arabidopsis KOR gene has been identified with the dwarf mutant KORRIGAN and found to be involved in normal wall assembly and cell elongation (Nicol et al., 1998). In G. barbadense the Cel gene is involved in cotton fiber elongation (Zhu et al., 2011). Our phylogenetic analysis revealed that the TaEG genes clustered more closely with $O$. sativa OsGLU1. Furthermore, alignment analysis demonstrated that TaEG shared more identity with OsGLU1 (83\%) than other membrane-anchored EGases. These findings suggest that TaEG is an ortholog of $O$. sativa OsGLU1 and may have similar biological roles. The $O$. sativa OsGLU1 gene has been identified with the dwarf mutant $g l u$ and found to be involved in cell elongation, cellulose and pectin content (Zhou et al., 2006).

Expression analysis showed that the highest levels of TaEG mRNA occurred in the 7-10 mm stage of CM28TP spikes. CM28TP has two more pistils per floret than CM28 and young spikes at the $7-10 \mathrm{~mm}$ stage in the primordial differentiation phase of subsidiary pistils (Yang et al., 2011). Based on these observations, we suggest that TaEG may contribute to pistil development and could be functionally important in defining the morphology of the three pistil mutant. However, this suggestion requires confirmation through additional experiments.

\section{Acknowledgments}

This work was supported by the National Natural Science Foundation of China (grant no. 30871533) and the Scientific Research Fund of Sichuan Provincial Education Department (grant no. 12ZB325).

\section{References}

Beguin P (1990) Molecular biology of cellulose degradation. Annu Rev Microbiol 44:219-248.

Beguin P and Aubert JP (1994) The biological degradation of cellulose. FEMS Microbiol Rev 13:25-58.

Bisaria VS and Mishra S (1989) Regulatory aspects of cellulase biosynthesis and secretion. Crit Rev Biotechnol 9:61-103.

Brummell DA, Bird CR, Schuch W and Bennett AB (1997b) An endo-1,4- $\beta$-glucanase expressed at high levels in rapidly expanding tissues. Plant Mol Biol 33:87-95.

Brummell DA, Catala C, Lashbrook CC and Bennett AB (1997a) A membrane-anchored E-type endo-1,4- $\beta$-glucanase is localized on Golgi and plasma membranes of higher plants. Proc Natl Acad Sci USA 94:4794-4799.

Byrne KA, Lehnert SA, Johnson SE and Moore SS (1999) Isolation of a cDNA encoding a putative cellulase in the red claw crayfish Cherax quadricarinatus. Gene 239:317-324.

Christoffersen RE, Tucker ML and Laties GG (1984) Cellulase gene expression in repining avocado fruit: The accumulation of cellulase mRNA and proteins as demonstrated by cDNA hybridization and immunodetection. Plant Mol Biol 3:385391.

Del Campillo E (1999) Multiple endo-1,4- $\beta$-D-glucanase (cellulase) genes in Arabidopsis. Curr Top Dev Biol 46:39-61. 
Endo TR and Gill BS (1996) The deletion stocks of common wheat. J Hered 87:295-307.

Ferrarese L, Trainotti L, Moretto P, Polverino de Laureto P, Rascio N and Casadoro G (1995) Differential ethyleneinducible expression of cellulase in pepper plants. Plant Mol Biol 29:735-747.

Hama E, Takumi S, Ogihara Y and Murai K (2004) Pistillody is caused by alterations to the class-B MADS-box gene expression pattern in alloplasmic wheats. Planta 218:712-720.

Henrissat B, Claeyssens M, Tomme P, Lemesle L and Mornon JP (1989) Cellulase families revealed by hydrophobic cluster analysis. Gene 81:83-95.

Kemmerer EC and Tucker ML (1994) Comparative study of cellulases associated with adventitious root initiation, apical buds, and leaf, flower and pod abscission zones in soybean. Plant Physiol 104:557-562.

Lane DR, Wiedemeier A, Peng L, Hofte H, Vernhettes S, Desprez T, Hocart CH, Birch RJ, Baskin TI, Burn JE, et al. (2001) Temperature-sensitive alleles of RSW2 link the KORRIGAN endo-1,4- $\beta$-glucanase to cellulose synthesis and cytokinesis in Arabidopsis. Plant Physiol 126:278-288.

Lashbrook CC, Gonzalez-Bosch C and Bennett AB (1994) Two divergent endo- $\beta$-1,4-glucanase genes exhibit overlapping expression in ripening fruit and abscising flowers. Plant Cell 6:1485-1493.

Livak KJ and Schmittgen TD (2001) Analysis of relative gene expression data using real time quantitative PCR and the $2^{-\Delta \Delta \mathrm{Ct}}$ method. Methods 25:402-408.

Manickavelu A, Kambara K, Mishina K and Koba T (2007) An efficient method for purifying high quality RNA from wheat pistils. Colloids Surf B Biointerfaces 54:254-258.

Molhoj M, Jorgensen B, Ulvskov P and Borkhardt B (2001) Two Arabidopsis thaliana genes, KOR2 and KOR3, which encode membrane-anchored endo-1,4- $\beta$-D-glucanases, are differentially expressed in developing leaf trichomes and their support cells. Plant Mol Biol 46:263-275.

Nicol F, His I, Jauneau A, Vernhettes S, Canut H and Hofte H (1998) A plasma membrane-bound putative endo-1,4- $\beta$-Dglucanase is required for normal wall assembly and cell elongation in Arabidopsis. EMBO J 17:5563-5576.

Peng ZS (2003) A new mutation in wheat producing three pistils in a floret. J Agro Crop Sci 189:270-272.

Porebski S, Bailey LG and Baum BR (1997) Modification of a CTAB DNA extraction protocol for plants containing high polysaccharide and polyphenol components. Plant Mol Biol Rep 1:8-15.

Rosso MN, Favery B, Piotte C, Arthaud L, De Boer JM, Hussey RS, Bakker J, Baum TJ and Abad P (1999) Isolation of a cDNA encoding a $\beta$-1,4-endoglucanase in the root-knot nematode Meloidogyne incognita and expression analysis during plant parasitism. Mol Plant Microbe Interact 12:585-591.

Saitou N and Nei M (1987) The neighbor-joining method: A new method for reconstructing phylogenetic trees. Mol Biol Evol 4:406-425.

Sears ER (1954) The aneuploids of common wheat. Mo Agric Exp Stn Res Bull 572:1-58.

Tamura K, Dudley J, Nei M and Kumar S (2007) MEGA4: Molecular evolutionary genetics analysis (MEGA) software ver. 4.0. Mol Biol Evol 24:1596-1599.
Taylor JE, Coupe SA, Picton S and Roberts JA (1994) Characterization and accumulation pattern of an mRNA encoding an abscission-related $\beta$-1,4-glucanase from leaflets of Sambucus nigra. Plant Mol Biol 24:961-964.

Thompson JD, Higgins DG and Gibson TJ (1994) CLUSTAL W: Improving the sensitivity of progressive multiple sequence alignment through sequence weighting, position-specific gap penalties and weight matrix choice. Nucleic Acids Res 22:4673-4680.

Tucker ML, Sexton R, Del Campillo E and Lewis LN (1988) Bean abscission cellulase: Characterization of a cDNA clone and regulation of gene expression by ethylene and auxin. Plant Physiol 88:1257-1262.

Watanabe H, Noda H, Tokuda G and Lo N (1998) A cellulase gene of termite origin. Nature 394:330-331.

Yamada K, Saraike T, Shitsukawa N, Hirabayashi C, Takumi S and Murai K (2009) Class D and B sister MADS-box genes are associated with ectopic ovule formation in the pistil-like stamens of alloplasmic wheat (Triticum aestivum L.). Plant Mol Biol 71:1-14.

Yang ZJ, Peng ZS, Wei SH, Yu Y and Cai P (2011) Identification of differentially expressed genes in three pistils mutation in wheat using annealing control primer system. Gene 485:8184.

Yang ZJ, Peng ZS, Zhou YH, Peng LJ and Wei SH (2012) Evaluation on the genetic background of wheat near isogenic lines for three pistils character by SRAP markers. J Nucl Agri Sci $1: 22-27$

Zhou W, Takeda H, Liu XZ, Nakagawa N, Sakurai N, Huang J and Li YQ (2004) A novel endo-1,4- $\beta$-glucanase gene ( LlpCell) is exclusively expressed in pollen and pollen tubes of Lilium longiflorum. Acta Bot Sin 46:142-147.

Zhou HL, He SJ, Cao YR, Chen T, Du BX, Chu CC, Zhang JS and Chen SY (2006) OsGLU1, a putative membrane-bound endo-1,4- $\beta$-D-glucanase from rice, affects plant internode elongation. Plant Mol Biol 60:137-151.

Zhu HY, Han XY, Lv JH, Zhao L, Xu XY, Zhang TZ and Guo WZ (2011) Structure, expression differentiation and evolution of duplicated fiber developmental genes in Gossypium barbadense and G. hirsutum. BMC Plant Biol 11:40-54.

\section{Internet Resources}

GenScan software, http://genes.mit.edu/GENSCAN.html (accessed November 7, 2012).

ORF finder software, http://www.ncbi.nlm.nih.gov/gorf/gorf.html.

Swiss-Prot/TrEMBL tool for calculating isoelectric point and molecular mass, http://www.expasy.org/tools/pi_tool.html (accessed November 7, 2012).

SignalP 4.1 software for identifying signal peptide cleavage sites, http://www.cbs.dtu.dk/services/SignalP/ (accessed November 7, 2012).

SCOP software for detecting transmembrane helices, http://scop.mrc-lmb.cam.ac.uk/scop/ (accessed November 7, 2012).

Associate Editor: Houtan Noushmehr

License information: This is an open-access article distributed under the terms of the Creative Commons Attribution License, which permits unrestricted use, distribution, and reproduction in any medium, provided the original work is properly cited. 